\title{
QUANDO A RELIGIÃO (DES)COMUNICA A CIÊNCIA: O CATOLICISMO BRASILEIRO E A PANDEMIA DE COVID-19
}

\author{
Emanuel Freitas da Silva ${ }^{1}$ \\ Emerson José Sena da Silveira²
}

Resumo:

Pretende-se com este artigo analisar as posições institucionais do catolicismo brasileiro durante a pandemia do novo coronavírus, a partir da ideia de uma "comunicação política" da ciência pela religião. Tomaremos como material de análise documentos da Conferência Nacional dos Bispos do Brasil (CNBB), decisões de algumas (arqui)dioceses e, como contraponto, as posições de movimentos católicos conservadores em questionamento às recomendações sanitárias e eclesiais. Assim, norteiase pela seguinte questão: terá havido, neste momento, uma importante tensão entre a hierarquia, comprometida com a ciência, e parcela dos fiéis, quiçá mais próximos do negacionismo político em voga? 0 artigo está embasado em método qualitativo, com foco na revisão parcial de produções bibliográficas atinentes à temática e mapeamento analítico dos principais posicionamentos of iciais propostos pelos segmentos católicos referidos.

Palavras-chave: Catolicismo institucional; pandemia; catolicismo público.

Abstract:

The aim of this article is to analyze the institutional positions of Brazilian Catholicism during the pandemic of the new coronavirus, based on the idea of a "political communication" of science by religion. We will take as analysis material documents from the National Conference of Bishops of Brazil (CNBB), decisions of some (arch) dioceses and, as a counterpoint, the positions of conservative Catholic movements in question to the sanitary and ecclesial recommendations. Thus, it is guided by the following question: has there been, at this moment, an important tension between the hierarchy, committed to science, and the faithful, closer to the current political negativism? The article is based on a qualitative method, focusing on the partial review of bibliographic productions related to the theme and analytical mapping of the main official positions (editorials, speeches, notes, texts) proposed by the mentioned Catholic segments.

Keywords: Institutional Catholicism; pandemic; public catholicism.

\section{Introdução}

$\mathrm{Na}$ sexta-feira, 27 de março de 2020, quando o mundo contava com a marca expressiva de 586.140 infectados pelo novo corona vírus e mais de 25 mil mortos, uma cena inédita circulava e ratificava a gravidade da doença que, rapidamente, chegava às cidades e países: numa Praça de São Pedro completamente vazia, sozinho, o Papa

\footnotetext{
1 É docente do Curso de Ciências Sociais (UECE/FACEDI), dos Programas de Pós-Graduação em Sociologia e de Planejamento e Políticas Públicas (UECE). Possui Graduação e Mestrado em Ciências Sociais e Doutorado em Sociologia. Membro do Laboratório de Estudos de Processos Eleitorais e Mídia (LEPEM/UFC), destacando-se nos estudos em religião e política. Além de artigos em periódicos científicos, também analisa fatos políticos em artigos na imprensa local. ORCID: https: //orcid.org/0000-0001-6304-4316

2 Doutor em Ciência da Religião, antropólogo, professor associado do Departamento e do Programa de PósGraduação em Ciência da Religião da Universidade Federal de Juiz de Fora.
} 
Francisco celebrava um ritual penitencial por meio do qual concedia a benção Urbi et Orbi aos fiéis católicos do mundo inteiro. A concessão daquela benção, de modo virtual, tradicionalmente enviada nas festividades de Natal e Ano Novo, dava mostras de como o líder máximo do catolicismo não punha dúvidas sobre a gravidade da nova pandemia e não questionava as medidas de isolamento social recomendadas pelas autoridades sanitárias, tampouco se rendia às ondas de negacionismo científico que tomaria forma em discursos de inúmeros líderes religiosos e políticos.

O mundo veria, pois, a milenar Igreja Católica a corroborar o trabalho de contenção da pandemia que se ia propagando por diversos lugares, demonstrando, assim, um certo compromisso institucional com a ordem pública, que aqui entendermos como um “catolicismo público”.

Imagem 1. Papa Francisco na Praça de São Pedro

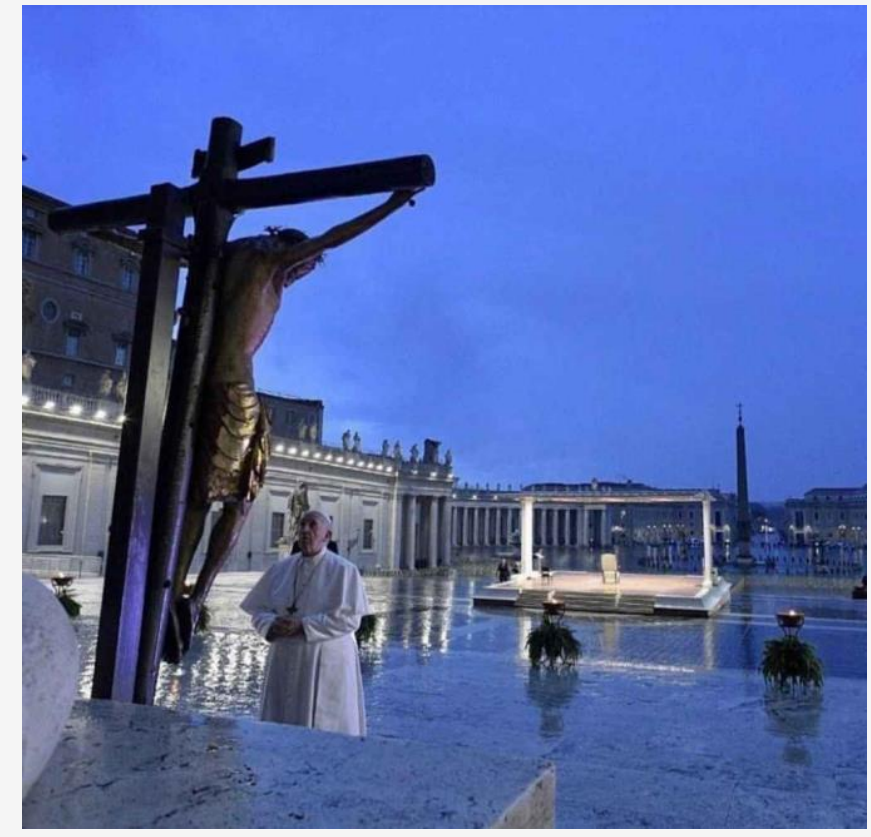

Fonte: MidiaMax.

Tradicionais celebrações do catolicismo, como os rituais da Semana Santa que se avizinhavam, seriam cancelados e realizados de forma remota. Também no Brasil, institucionalmente, a Igreja Católica acompanhou, por meio de posicionamentos públicos da Conferência Nacional dos Bispos do Brasil (CNBB), as recomendações das autoridades sanitárias no que diz respeito aos modos mais eficazes de se combater a propagação da Covid-19, com ênfase no isolamento social, o que implicava o fechamento das igrejas. 
A hipótese qualitativo-exploratória deste artigo demonstra que o momento da pandemia acentuou, em termos de dissonância comunicativa, as linhas de tensão existentes na Igreja Católica e, à medida que a pandemia recrudesceu, a marcha institucional da hierarquia católica se deu em sentido oposto ao trilhado por líderes evangélicos, que demonstraram maior e mais coeso apoio às medidas e à comunicação do governo brasileiro. 0 artigo está embasado em método qualitativo, com foco na revisão parcial de produções bibliográficas atinentes à temática e mapeamento analítico dos principais posicionamentos oficiais propostos pelos segmentos católicos referidos a partir da escolha dos sites e imagens escolhidos segundos os critérios de carga semântica (capacidade de mobilização), índice institucional (o quanto representam a visão institucional da igreja) e capacidade comunicativa ampla. O objetivo é, pois, analisar tais posicionamentos da CNBB a partir da ideia de uma comunicação religiosa que promoveria a comunicação científica no momento de propagação da pandemia. Tal comunicação, porém, não se daria sem fissuras e tensões no interior do próprio catolicismo.

No cenário confuso de choques entre as orientações presidenciais, as dos governadores e prefeitos e as da $\mathrm{OMS}^{3}$, lideranças religiosas, algumas delas católicas, embora não as oficiais, como a CNBB (Conferência Nacional dos Bispos do Brasil), se alinharam ao Presidente Jair Bolsonaro, sobretudo quanto à interrupção dos serviços e o fechamento dos templos como forma de colaboração com as medidas de isolamento (BANDEIRA; CARRANZA, 2020). Em diversas ocasiões, elites pastorais e elites parlamentares evangélicas e católicas defenderam publicamente o fim ou o relaxamento de medidas restritivas, em especial as que limitavam a frequência a cultos e serviços religiosos e a adoção da cloroquina, remédio sem eficácia comprovada ${ }^{4}$.

A comunicação tornou-se ideologicamente orientada para uma visão quase ufanista, repercutindo o mote da campanha presidencial bolsonarista de 2018, "Deus acima de tudo, Brasil acima de todos". Os argumentos usados para contestar medidas restritivas eram o princípio da liberdade religiosa/liberdade de expressão, posto como se fosse absoluto ainda que diante de uma grave emergência de saúde pública, a divulgação de anúncios de curas $^{5}$ ou promessas de imunização contra o vírus, a ideia de que as igrejas seriam "serviço

\footnotetext{
${ }^{3} 0$ Presidente Bolsonaro, em transmissão online pelo Facebook, ao lado de Mandetta, médico e então ministro da saúde, anunciou a cloroquina como panaceia curativa. Após, o anúncio, as redes sociais dos líderes evangélicos e nas pregações, passaram a repetir as falsas informações passadas durante a live presidencial.

${ }^{4}$ Ver a reportagem Le Monde. Au Brésil, des évangéliques nient la dangerosité du coronavirus. Disponível em: https://marketingeditorare.wixsite.com/ebooks. Acesso em: 26 jul. 2020.

5 Mesmo exorcismos chegaram a ser prometidos como cura do vírus a fiéis católicos. Sobre isso, ver: https://www.bbc.com/portuguese/internacional-52986252.
} 
essencial" - com uma dupla tarefa, a espiritual e a assistencial - e a minimização dos efeitos de medidas mais rigorosas adotadas por governadores e prefeitos (BANDEIRA; CARRANZA, 2020). ${ }^{6}$

Os argumentos favoráveis às medidas restritivas usados por alguns grupos religiosos passavam pela valorização da ciência, das políticas de saúde públicas pautadas por conhecimento reflexivo-racional-político, pela busca do equilíbrio entre princípios, sem tornar absolutos os da liberdade de ir e vir e o de expressão/crença em detrimento do direito à saúde e educação para todos, e o seguimento de orientações pastorais de líderes mais afinados com discussões políticas e econômicas que buscavam entender e atenuar os múltiplos impactos sociais, sanitários, econômicos (pobreza e desigualdade de riqueza, renda e raça) acentuados pelo avanço da COVID-19.

\section{A CNBB e a COVID-19}

Surgida nos anos 1950, no bojo das mudanças sociais e religiosas que culminaram com o Concílio Vaticano II, o grupo organizado de bispos pretende e é tomado como a voz oficial da ICAR (Igreja Católica Apostólica Romana) no Brasil e como a voz da Igreja Católica do Brasil. Terceira conferência de bispos criada no mundo, ${ }^{7}$ sua composição administrativa é simples: uma presidência, duas vice-presidências, uma secretaria geral, comissões, pastorais, comissões ${ }^{8}$, filiais e regionais (18 unidades). Suas tensões internas refletem as distintas concepções de religião católica e os papéis que ela deveria, idealmente, cumprir na sociedade e no espaço público (KLAIBER, 1998).

Poderíamos pensar, aqui, na Teoria Geral dos Campos $^{9}$ de Bourdieu (2003; 2004; 2005). Um campo é o universo simbólico-social, concreto e abstrato, em que o mundo de determinado grupo produz e reproduz para si, para os outros e para o próprio campo (em conflito, aliança e disputa), regras, hierarquizações, classificações, normas, discursos, valorações e desclassificações. O objetivo maior é aumentar a fazer circular o capital

\footnotetext{
${ }^{6}$ Não vamos nos aprofundar, mas a COVID-19 provocou um forte choque entre os entes republicanos, a União e os estados. O Supremo tribunal Federal, em decisão recente, definiu que ambos os entes possuem autoridade e autonomia para impor medidas restritivas, propor e implantar políticas de combate.

7 Para conhecer uma visão interna de sua história, ver: https://www.cnbb.org.br/a-estrutura-administrativa-epastoral-da-cnbb-tem-uma-matriz-e-18-unidades-regionais/ Acesso em: 26 jul. 2020.

${ }^{8}$ As mais famosas, inclusive pelo enfrentamento que fazem aos governos, desde o governo militar (1965-1985), até o atual (2018-2022), estão CIMI/Conselho Indigenista Missionário; CPT/Comissão Pastoral da Terra; CEFEP/Centro Nacional de Fé e Política; CBJP/Comissão Brasileira de Justiça e Paz.

9 É preciso, todavia, alertar para os limites teórico-metodológicos das teorias de Bourdieu, por exemplo, uma insuficiência teórica para entender as complexas interações entre economia, política e cultura dentro de perspectivas sociorreligiosas.
} 
simbólico. Aplicado ao campo católico, temos que as disputas por capital simbólico religioso se dá entre agentes, grupos e posições estabelecidos e consolidados institucionalmente - que marcham favoráveis à ciência, como a CNBB - e agentes, grupos e posições destituídos desse capital, mas que estão em busca de cacife simbólico-social a partir de uma negação da ciência e, também, nesse caso, ajudado pela influência do campo político atual (o governo Bolsonaro e seu extremo reacionarismo político-religioso).

Por outro lado, para interpretar essas tensões, não nos deteremos sobre sua grande importância na longa história de atuação, suas querelas públicas com a Ditadura Militar (1964-1985), com o Estado brasileiro, suas relações com outros organismos católicos, sua famosa Campanha da Fraternidade por ocasião do tempo litúrgico (Quaresma, Semana Santa), muito marcada por causas sociais, que pauta todas as paróquias/dioceses brasileiras, suas lutas pelos direitos humanos e a favor dos povos originários (BRUNEAU, 1985; KLAIBER, 1998) dentre outros elementos de sua importante atuação na história social republicana do país. Ao artigo interessa tomar seu discurso frente ao letal avanço da COVID-19 pelo Brasil.

No caso dos discursos oficiais sobre a pandemia, tema central do artigo, o mapeamento identificou sete "palavras oficiais" da CNBB, como são chamadas as notas/falas da instituição e da sua presidência. O portal eletrônico oficial é simples, com links que conduzem para sua estruturação interna, atividade, notícias e abas (palavra oficial, ministérios, catequese, família, liturgia, cultura e educação, ecumenismo, doutrina, juventude, comunicação, missão, laicato, Amazônia). Os posicionamentos, agrupadas sob a aba "Palavra Oficial" são os seguintes: 


\section{Quadro 1. Notas/Falas Oficiais ${ }^{10}$}

11/05/2020 - Presidente da CNBB emite nota sobre a discussão da MP 910 da regularização fundiária. No texto, o arcebispo de Belo Horizonte (MG), dom Walmor Oliveira de Azevedo, reitera a posição da Conferência cujo dever cristão é defender a vida, principalmente dos pobres, e da natureza. Menciona, levemente, a crise sanitária da pandemia

30/04/2020 - Título: "Mensagem Do Presidente da Conferência Nacional dos Bispos do Brasil aos trabalhadores e trabalhadoras do Brasil". Homenagem ao dia do trabalhador, com referência à crise sanitária e ao papel do Estado e remete à fala do Papa Francisco sobre o trabalho digno e justo para todos.

30/04/2020 - Título: "Em Defesa Da Democracia, Pela Justiça E Pela Paz! A CNBB conclama a sociedade e os responsáveis pelos poderes públicos a se unirem pela prevenção e pelo combate à Covid-19. Por meio de nota, a CNBB considera que esta é a mais grave crise sanitária dos últimos tempos e afirma ser este um momento difícil, que clama pelo exercício da solidariedade e da caridade.

24/04/2020 - Fala Oficial do presidente da CNBB nas redes sociais: "A mudança no Ministério da Justiça evidencia intervenção política no comando de instituições que, nos parâmetros da Constituição Federal, devem e não podem deixar de ter autonomia e independência”. O presidente da CNBB, dom Walmor Oliveira de Azevedo, manifesta-se nas redes sociais.

18, 19 e 23/04/2020 - Título: "Em defesa da vida: É tempo de cuidar". Conclama o apoio contra o aborto. A nota é uma resposta ao fato de o STF ter agendado o julgamento da ADI 5581 (liberação do aborto em caso de Zika vírus). No texto, a presidência da CNBB demonstra preocupação e perplexidade, neste tempo de pandemia, com a decisão do Supremo Tribunal Federal (STF) de pautar para a próxima sexta, dia 24 de abril, o tratamento da Ação Direta de Inconstitucionalidade - ADI 5581

15/03/2020 - Título: Tempos de esperança e solidariedade. A mensagem pede observação irrestrita às orientações médico-sanitárias, manifesta preocupação com as mudanças nos cultos e celebrações, pede atenção

Em geral, esses posicionamentos são repercutidos por toda cadeia de comunicação católica, exceto em sites e portais conservadores e reacionários, que costumam ou ignorar ou deixar como simples registro. A primeira nota é emitida vinte dias depois do registro do primeiro caso no Brasil, curta, com sete pontos. Àquela altura dos acontecimentos, o mundo e o Brasil assistiam com pavor, o avanço da pandemia na Europa, especialmente na Itália e na Espanha ${ }^{11}$. No campo da comunicação, as plataformas digitais e as grandes empresas de comunicação no Brasil, davam grande destaque às medidas restritivas

10 O quadro foi criado a partir das informações disponíveis nesta página eletrônica https://www.cnbb.org.br/category/palavra-oficial/ Acesso em: 26 jul. 2020.

11 No Brasil, naquela data havia apenas 79 casos confirmados. 
adotadas por governos europeus. No período mais difícil da pandemia, padres e bispos europeus morreram porque foram contaminados com o novo coronavírus.

As primeiras orientações estavam sendo tomadas no Brasil, e em ato contínuo, houve uma disputa entre o ministro da saúde, alguns governadores e prefeitos e o presidente a respeito das medidas restritivas. Um dos trechos do primeiro ponto da nota dizia:

Recomendamos atenção e consideração irrestrita às orientações dos especialistas de saúde e autoridades competentes. As indicações sobre o modo como celebrar a fé cabem aos bispos em cada diocese. Todas as normas visam à proteção das pessoas, buscando evitar a contaminação e preservar a vida ${ }^{12}$.

No ponto quatro, o documento dizia: “Aproveitemos para pensar nos inúmeros outros modos em que a vida de pessoas, povos e do planeta vem sendo agredida." ${ }^{13}$. No restante, fala-se da importância da tecnologia para suprir a distância física, da pratica da caridade e solidariedade, mas, seguido as orientações médico-sanitárias.

Por volta de um mês depois do primeiro caso registrado de COVID-19, a CNBB lançou uma segunda nota oficial, com sete pontos (numerados), em que o objetivo maior era intervir no debate jurídico sobre a permissão ou não do aborto em casos de má-formação do feto por conta do Zika-Vírus. ${ }^{14} \mathrm{O}$ tom é solene, afirma algo que não é afirmado na nota anterior, a saber, toda autoridade de ser ela, a CNBB, a voz do catolicismo na sociedade brasileira:

A Presidência da Conferência Nacional dos Bispos do Brasil, porta-voz da Igreja Católica na sociedade brasileira em sintonia com segmentos, instituições, homens e mulheres de boa vontade, convoca a todos pelo empenho em defesa da vida, contra o aborto, e se dirige, publicamente, como o faz em carta pessoal, aos Senhores e Senhoras Ministros do Supremo Tribunal Federal $[\ldots]^{15}$

O segundo ponto é uma crítica ao fato de o STF marcar o julgamento em meio à crise pandêmica. Contra isso, a CNBB afirma: “Preocupa-nos e nos causa perplexidades, no

\footnotetext{
12 Disponível em: https://www.cnbb.org.br/cnbb-emite-mensagem-na-qual-pede-observacao-irrestrita-asorientacoes-medico-sanitarias/ Acesso em: 26 jul. 2020.

13 Idem, ibidem.

14 Tratou-se de um julgamento feito pelo STF (Supremo Tribunal Federal) sobre a constitucionalidade dos pedidos de aborto de mães que tenham gerados fetos com graves deformidades incapacitantes por toda vida. 0 Zika-Vírus é mais de uma grande família de vírus que passou a circular no mundo, e no Brasil, a partir da África. Está relacionado as más condições de tratamento de água e esgoto, a pobreza absoluta.

${ }^{15}$ Disponível em: https://www.cnbb.org.br/a-presidencia-da-cnbb-publica-a-nota-em-defesa-da-vida-e-tempode-cuidar-para-pedir-a-todos-o-empenho-pela-o-defesa-da-vida/ Acesso em: 26 jul. 2020.
} 
grave momento de luta sanitária pela vida, neste tempo de pandemia do COVID-19, desafiados a cuidar e amparar muitos pobres e empobrecidos pelo agravamento da crise econômico-financeira" $[\ldots]^{16}$.

Àquela altura, a COVID-19, que tinha chegado ao Brasil por meio de viajantes de classe média alta/rica que tinham visitado regiões europeias contaminadas, alastrou-se muito entre as camadas populares, entre as áreas mais precárias e miseráveis das cidades. As medidas muito restritivas, tomadas por governadores e prefeitos, afetavam a economia, produzindo depressão, pobreza e aumentando a miséria. 0 governo federal vinha seguindo uma linha de ação neoliberal demorando a esboçar algum tipo de política pública de apoio social-econômico. Mais do que o desmonte do Estado de Bem-Estar Social, característica do liberalismo no século XX, o atual neoliberalismo evidencia uma intervenção ativa na estrutura socioeconômica, pelas mãos do Estado, para aumentar a acumulação de maisvalia no setor privado financeiro, que hegemoniza os demais setores do capitalismo.

Por outro lado, o presidente Jair Bolsonaro envolvia-se em polêmicas e controvérsias, negando a gravidade da pandemia e a validade das medidas restritivas, com ações que privilegiavam setores religiosos, como a que considerava as igrejas como serviços essenciais, ou seja, serviços que não precisariam ser fechados ou parados ${ }^{17}$.

No resto da segunda nota, a CNBB protesta contra o aborto, citando a cartaencíclica papal de João Paulo II (Evangelium Vitae). No ponto quadro, a CNBB finca pé: “Não compete a nenhuma autoridade pública reconhecer seletivamente o direito à vida, assegurando-o a alguns e negando-o a outros. Essa discriminação é iníqua e excludente $[\ldots]^{\prime \prime}{ }^{18}$

O terceiro posicionamento é uma fala oficial, mas apenas do presidente da CNBB, e versa sobre um assunto especifico: a demissão do ex-juiz (Sérgio Moro) que, após condenar um ex-presidente brasileiro (Lula da Silva), então candidato em 2018, aceitou o convite do governo Bolsonaro para ser ministro da justiça. Dom Walmor Oliveira de Azevedo afirma, sem nomear diretamente a polêmica da demissão, que foi uma intervenção política no comando das instituições republicanas. Não há, nesta nota, nenhuma referência a COVID19.

\footnotetext{
16 Disponível em: https://www.cnbb.org.br/a-presidencia-da-cnbb-publica-a-nota-em-defesa-da-vida-etempo-de-cuidar-para-pedir-a-todos-o-empenho-pela-o-defesa-da-vida/ Acesso em: 26 jul. 2020.

170 presidente assinaria, em 26 de março, um decreto presidencial em que se reconhecia lotéricas e igrejas como "atividades essenciais", que seria derrubado dias depois por uma decisão em primeira instância e, depois pelo próprio STF, que garantia aos prefeitos e governadores a competência para incluir ou não setores nas atividades essenciais nos territórios por estes governados.

18 Idem, ibidem.
} 
O quarto posicionamento, é uma nota oficial, assinada por todo comando da CNBB, reafirmando um documento anterior, chamado "Pacto pela Vida e pelo Brasil", lançado no dia 7 de abril, assinado por 156 instituições e associações civis brasileiras. 0 tom do texto é forte: "Diante da mais grave crise sanitária dos últimos tempos, com o sistema de saúde já entrando na fase de colapso, consideramos este momento dificílimo, que clama pelo efetivo exercício da solidariedade e da caridade". E, diante do pandemônio causado pelo presidente dentro da grave crise pandêmica do novo coronavírus, a nota da CNBB faz referência aos atos de apoiadores do governo que, reunidos massivamente diante do Palácio Presidencial, pediam o fechamento do Congresso Nacional e o STF (Supremo Tribunal Federal):

É com perplexidade e indignação que assistimos manifestações violentas contra as medidas de prevenção ao coronavírus; que ouvimos declarações enviesadas de desprezo pela vida, por parte de agentes públicos sobre a morte de milhares de brasileiros e brasileiras contaminados pelo covid-19; que vimos acontecer eventos atentatórios à ordem constitucional, com a participação de autoridades públicas, onde se defendeu o fechamento do Congresso Nacional e do Supremo Tribunal Federal, a volta do Al-519 e o retorno aos sombrios tempos da ditadura; que todo o Brasil soube de denúncias acerca da politização da justiça, ferindo sua necessária autonomia de investigação. ${ }^{20}$

A nota segue na contramão da atuação e das falas presidenciais, que defendiam a abertura geral do comércio, o relaxamento da quarentena e das medidas restritivas, enfim, a economia como vida da nação, em detrimento dos mais pobres, dos que estão desassistidos de políticas públicas:

O cuidado da saúde das pessoas e da economia são fundamentais para a garantia da vida em sua plenitude e não se opõem. Na perspectiva da Doutrina Social da Igreja, a economia está a serviço da vida: "o princípio da destinação universal dos bens convida a cultivar uma visão da economia inspirada em valores morais que permitam nunca perder de vista nem a origem, nem a finalidade de tais bens, de modo a realizar um mundo equitativo e solidário, em que a formação da riqueza possa assumir uma função positiva." (CDSI, 174). ${ }^{21}$

A nota procura criticar a divisão entre saúde e cuidado da economia, dicotomia inúmeras vezes acionada pelo presidente e seus apoiadores, e termina com um apelo à

\footnotetext{
${ }^{19}$ Referência ao ato mais autoritário, duro e ditatorial tomado pelo regime militar brasileiro em 1968.

20 Disponível em: https://www.cnbb.org.br/cnbb-conclama-a-sociedade-e-os-responsaveis-pelos-poderespublicos-a-se-unirem-a-prevencao-e-o-combate-a-covid-19/ Acesso em: 26 jul. 2020.

21 Idem, ibidem.
}

// REVISTA DISPOSITIVA, v. 9, n. 16, p. 188-206 - ago/dez (2020) 
padroeira do Brasil, Nossa Senhora Aparecida. Logo em seguida, temos um quinto posicionamento, a segunda fala oficial, ${ }^{22}$ restrita ao presidente da CNBB, reforçando a nota oficial (o quarto posicionamento) e em comemoração ao dia do trabalho, 01 de maio. Dom Walmor critica a desigualdade social e aponta a existência de uma “lógica econômica perversa". A fala menciona a crise sanitária, social e econômica, reconhece a gravidade dos problemas e afirma:

O Estado tem o dever de dar prioridade aos trabalhadores e trabalhadoras brasileiras em situação de vulnerabilidade. É fundamental que o Estado adote políticas claras na contramão dos interesses espúrios do lucro e dos privilégios excludentes, vergonhosos e injustos. É urgente uma economia que se volte para o desenvolvimento integral, preservando emprego, renda e trabalho na cidade e no campo. Aí, especialmente, não permitindo legislações que não favoreçam o desmonte da sobrevivência do camponês. A você trabalhador que está sofrendo as consequências da crise sanitária e política: saiba que você não está sozinho. Enquanto ela persiste, Deus está do seu lado - Deus estará sempre do seu lado. A solidariedade é o grande remédio para um mundo novo, justo e fraterno. Estamos juntos nessa travessia e sairemos mais forte dela. Sejamos guiados pela esperança e pela fé. ${ }^{23}$

A CNBB exigia que o Estado priorizasse os trabalhadores em situação precária durante a pandemia, que adote políticas públicas amplas e contrárias a privilégios e “interesses espúrios do lucro". ${ }^{24}$ A fala oficial termina com um apelo a São Jose Operário, patrono da Igreja e do(a)s trabalhadores, e termina com o apela a uma sociedade justa, fraterna e solidária.

Por fim, o último posicionamento oficial que consta na página é uma nota escrita emitida em 11 de maio de $2020^{25}$ pelo presidente da CNBB fazendo referências à Encíclica Laudato Si, do Papa Francisco. A nota da presidência critica a iminente votação, por parte do Congresso Nacional, de uma legislação federal que trata da regularização fundiária. 0 argumento seria o "contexto singular de crise sanitária, econômica e política, atravessado pelo Brasil"26 e porque se trata de "[...] um tema complexo, que envolve o patrimônio da

\footnotetext{
22 Gravado em vídeo no canal da CNBB no Youtube. Disponível em: https: / / www.youtube.com/watch?v=3bSg3w6GlqQ\&feature=youtu. be Acesso em: 26 jul. 2020.

23 Disponível em: https://www.cnbb.org.br/mensagem-do-presidente-da-cnbb-aos-trabalhadores-as-do-brasilo-momento-e-de-uniao-de-esforcos-publico-e-privado-para-que-ninguem-seja-deixado-para-tras/ Acesso em: 26 jul. 2020.

24 Idem, ibidem.

25 Disponível em: https://www.cnbb.org.br/presidente-da-cnbb-emite-nota-sobre-a-discussao-da-mp-910-daregularizacao-fundiaria/ Acesso em: 26 jul. 2020.

${ }^{26}$ Idem, ibidem.
} 
união, questões ambientais, grilagem de terras e, consequentemente a violência no campo, bem como, diversos interesses.". ${ }^{27}$

O Governo Federal publicara um decreto $\left(n^{\circ}\right.$ 10.292) em junho de 2020 que elegia o culto religioso como atividade essencial durante a pandemia. Pouco depois, é divulgada, nas redes de comunicação institucionais do catolicismo, uma crítica da CNBB, em comunicado assinada pelo secretário-geral, dom Joel Portella Amado:

[...] orientações emanadas pelas autoridades competentes do Ministério da Saúde indicam o distanciamento social, as igrejas, se os bispos assim o considerarem, podem permanecer abertas, porém, do modo como tem sido feito: orações individuais, transmissões online etc. Não há como entender que os instrumentos legais acima referidos possam obrigar a reabertura das igrejas, muito menos para a prática de qualquer tipo de aglomeração $0^{28}$.

Por ser um dos mais poderosos organismos da Igreja Católica, a CNBB, que se apresenta como o porta-voz do catolicismo na sociedade brasileira, em tese, forneceria os caminhos a serem seguidos por outros grupos católicos organizados em pelo menos dois sentidos propostos neste artigo: a reprodução ou a referências as falas e pronunciamentos oficiais ou a produção de posicionamentos próprios, mas inspirados nas diretrizes gerais oferecidas pela associação dos bispos brasileiros.

Apesar de não constar entre as notas publicadas na "palavra oficial" do site da CNBB, uma outra nota seria assinada pela entidade, junto com outras instituições (OAB, Comissão Zilda Arns, Academia Brasileira de Ciências, Associação Brasileira de Imprensa e Sociedade Brasileira para o Progresso da Ciência), com a assinatura dos presidentes de cada uma delas, e publicada em 05 de junho, sob o título "Unidos, solidários e mobilizados".

Prestando solidariedade às vítimas da pandemia no país, a nota denunciava a "inexistência de um plano nacional de saúde", a "morosidade para a liberação de recursos emergenciais" e alertava para a necessidade de que o trato da pandemia no Brasil estivesse "apoiada na melhor ciência e condicionada pelos princípios fundamentais da dignidade humana e da proteção da vida", atacando, assim, frontalmente o governo Bolsonaro em três aspectos.

A nota se encerrava com as seguintes palavras:

\footnotetext{
27 Idem, ibidem.

28 Disponível em: https://g1.globo.com/politica/noticia/2020/03/26/lideres-religiosos-comentam-decreto-debolsonaro-que-torna-atividades-religiosas-essenciais-em-meio-ao-coronavirus.ghtml Acesso em: 26 jul. 2020.
} 
0 desejo cidadão de flexibilizar o isolamento social para sair às ruas em defesa da democracia e da Constituição não pode ser realizado agora, considerando-se os riscos de contaminação. É uma atitude legítima diante do discurso autoritário que se alastra pelo país, em momento tão grave. Porém, com lucidez, não se deve cair na armadilha de grupos extremados, cujo único objetivo é o de provocar confrontos, gerando instabilidade e comprometendo a cidadania. Por isso, consideramos fundamental: manter o distanciamento social recomendado pela OMS; a partir das nossas casas, fortalecer a união de todos os brasileiros no combate à Covid-19 e na defesa das nossas instituições; cobrar o fortalecimento do SUS e a ajuda emergencial aos necessitados; e exigir rigor e transparência na divulgação de dados sobre a evolução da pandemia no Brasil. Fiquemos em casa pela vida e pela democracia - unidos, solidários e mobilizados (Disponível em: https://www.cnbb.org.br/wp-

content/uploads/sites/32/2020/06/NOTA_Unidos-solida\%CC\%81rios-emobilizados-05062020.pdf. Acesso em: 03 ago. 2020).

Além destes pronunciamentos oficiais da CNBB, decisões de alguns bispos brasileiros também, deram mostras de uma considerável colaboração da hierarquia católica com as decisões de autoridades governamentais, ancoradas nas recomendações sanitárias, para a contenção da Covid-19. À guisa de exemplo, vejamos o seguinte caso. No estado do Amazonas, um projeto de lei foi apresentado pelo deputado João Luiz (REPUBLICANOS), que é pastor da Igreja Universal do Reino de Deus e presidente da Frente Parlamentar Cristã na Assembleia Legislativa, e aprovado em 07 de maio de 2020, data em que o estado apresentava mais de 10 mil casos confirmados de Covid-19 (quase 6 mil só em Manaus) e 856 óbitos causados pela doença, 563 na capital. O projeto de lei proposto, em resposta ao decreto do governador Wilson Lima (PSL) que havia determinado o fechamento de templos e igrejas, passava a considerar como de "serviço essencial" as atividades desenvolvidas pelas igrejas; foi aprovado por 21 dos deputados presentes, tendo recebido apenas 2 votos contrários, cujos deputados alegaram "equívoco" aquilo que estava proposto ali"

Segundo o autor do projeto, "as igrejas e templos estarão atendendo a uma série de recomendações de prevenção contra o coronavírus. A proposta é garantir à população amazonense o apoio necessário para este momento crítico". Por sua vez, o relator do projeto, deputado Dr. Gomes (PSC), informou em seu parecer que "com o confinamento, o ser humano luta contra um problema imperceptível, que é o lado psicológico e emocional. Por isso, as igrejas são essenciais, por acolher e acalmar o cidadão que busca a ajuda necessária para lidar com a situação". Logo, as recomendações da ciência traziam uma série de problemas para os quais ela mesma não seria capaz de responder, cabendo à

29 Disponível em: https://www.brasildefato.com.br/2020/05/07/mesmo-com-caos-pela-pandemia-deputadosdo-amazonas-liberam-reabertura-de-igrejas Acesso em: 23 jul. 2020. 
religião, cristã, o papel de resposta corretiva aos problemas produzidos pelo cumprimento das recomendações científicas ${ }^{30}$.

Apesar das medidas de restrição que se imporiam aos templos presentes no texto do projeto, o mais importante aqui é a inscrição das igrejas como "serviço essencial", algo que aqui nos interessa. Voltaremos mais adiante a isso. Mesmo diante da aprovação do projeto, o arcebispo de Manaus, Dom Leonardo Steiner, ordenou que o distanciamento social continuasse a ser praticado pelos católicos do estado, para isso determinando que os templos católicos continuassem fechados ${ }^{31}$.

Tensões e fissuras no interior do catolicismo - "não estamos com a CNBB" (?)

Os ativistas católicos conservadores estabeleceram aproximações com os coletivos evangélicos similares. Entendemos que parcela significativa desses católicos compõe o processo social de alcance mais amplo denominado no debate público de onda conservadora, a qual articula, em níveis diferentes, pelo menos quatro linhas de forças sociais: economicamente liberal, moralmente reguladora, socialmente intolerante e punitiva (ALMEIDA, 2019). Esses segmentos cristãos atuam buscando restaurar a ordem moral e social tradicional tida sob ataque de "forças malignas". As lutas antigênero, anticiência e antipluralismo reproduzem repertórios morais e batalhas políticas da direita cristã e também do Vaticano, como a noção de "ideologia de gênero", arma ideológica que se tornou onipresente nos pleitos e disputas parlamentares na região (SILVEIRA, 2019).

A rejeição ao PT (Partido dos Trabalhadores) e um anti-comunismo anacrônico passaram a nortear crescentemente posições políticas de líderes e deputados cristãos conservadores. Cada vez mais estes passaram a se identificar como conservadores, a se aliar a grupos de direita, a atacar os direitos humanos, a educação sexual nas escolas e as políticas anti-homofóbicas (MARIANO; GERARDI, 2019). Assim, a partir da eleição de Jair Bolsonaro é possível identificar um perfil cristofascista em parte da militância católica conservadora (PY, 2020 a; 2020 b).

\footnotetext{
${ }^{30}$ A ideia da religião como "alimento espiritual" esteve presente na argumentação de muitos dos deputados que votaram a favor do projeto, como se pode ver em: https://amazonasatual.com.br/assembleia-doamazonas-aprova-projeto-que-reabre-igrejas-e-tempos-na-pandemia/. A ideia de "alimento" confere o caráter de "serviço essencial" pretendido pelas igrejas.

31 De igual modo, o arcebispo de Fortaleza (CE) também adotaria recomendações de maior isolamento social, adiando a reabertura de templos católicos no Ceará. Ver: https: / /igrejasaobenedito.com.br/2020/05/12/deveremos-seguir-em-tudo-o-que-foi-decretado-pedearcebispo-a-agentes-da-pascom/.
} 
Assim como os evangélicos, os discursos de lideranças do movimento carismático reforçam o papel de Bolsonaro na defesa de uma "nação brasileira cristã", cujos valores ético-morais deveriam orientar toda a sociedade e inspirar a formulação de políticas públicas. Tais agentes religiosos reconhecem nele a posse do capital simbólico de "presidente dos cristãos", consolida a imagem do Brasil como nação cristã e reforça o caráter religioso nas determinações do Presidente, elevando-o a "novo messias prestes a salvar o Brasil" (PY, 2020 b).

O presidente convocou um dia nacional de jejum, uma semana antes da Páscoa cristã (07/04/2020), rezou ajoelhado na portaria do Palácio da Alvorada, ergueu uma imagem de Jesus Misericordioso na rampa do Planalto e promoveu a citada videoconferência com líderes religiosos na Páscoa, com evangélicos e católicos, sem autorização ou comunicação prévia à CNBB, que se coloca e é vista, por amplos grupos sociais, religiosos e nãoreligiosos, como porta voz do catolicismo na sociedade brasileira.

Dois movimentos, pois, dentro do catolicismo brasileiro exporiam, em termos de comunicação política, as tensões e fissuras com relação às posturas frente às recomendações para o combate à pandemia, explicitando as tensões no interior daquela que ainda se arvora a qualificação de "maior religião do país". Optamos analisar aqui neste espaço mensagens apócrifas, em vídeos e textos, compartilhadas em redes sociais de movimentos católicos tradicionalistas e da renovação carismática durante os meses de abril de maio de 2020.

O primeiro deles, organizado internacionalmente e expresso também no país, intitulava-se como um movimento que bradava aos bispos, comprometidos com o isolamento social: “Devolvam-nos a eucaristia!” ou "Devolvam-nos a missa!"32. Uma série de textos e vídeos foram publicados nas redes sociais, numa intensa mobilização laical pela reabertura das igrejas, o que implicava um pedido-ordem diretamente direcionada aos bispos.

Um vídeo compartilhado pela página "católico oficial" apresentava um conjunto de jovens que liam um texto do qual recortamos o seguinte trecho:

Queridos bispos do Brasil, sabemos que são tempos difíceis, mas nós temos um pedido: por favor, nos devolvam a santa missa. Já começou a ser permitido a abertura de pequenas lojas. As lojas que vendem produtos básicos estiveram abertas durante todo o período de confinamento. 0 que

\footnotetext{
32 Sobre o movimento, ver: http://www.ihu.unisinos.br/78-noticias/598442-os-organizadores-do-devolvam-nos-
} a-missa-sao-os-mesmos-que-lancam-campanhas-contra-os-bispos-espanhois-argentinos-e-brasileiros. 
pode ser mais importante e essencial para nós do que a santa missa? 0 papa Francisco disse: a igreja é concreta, não pode permanecer virtual. Por favor, nos devolvam a santa missa (Disponível em: https: //www. youtube.com/watch?v=6ey7yQHebnU. Acesso em 03 ago. 2020).

A campanha fazia supor que era dos bispos a responsabilidade pela reabertura dos tempos e, mais do que isso, a ideia de que eram eles quem haviam retirado dos fiéis o ritual da comunhão: "devolvam-nos" sugere que foram eles que retiraram, mesmo usurparam. Era a eles, e não às autoridades públicas, que se responsabilizava pelo fechamento das igrejas, num duplo movimento em que, responsabilizando-os por isso os punha acima das autoridades políticas, dando aos bispos o poder de determinar a volta das igrejas. O vídeo termina com a frase repetida inúmeras vezes: "devolvam-nos a eucaristia". Assim, fiéis, de um lado, expressavam desejo de reabertura dos templos, contrariando recomendações sanitárias, políticas e eclesiásticas, aproximando-se das tomadas de posição do governo brasileiro ${ }^{33}$ e de setores do segmento evangélicos; por outro lado, bispos resistiam às investidas de fiéis que, desconhecendo a gravidade do momento, pediam o fim do isolamento social.

Um texto apócrifo, que circulou em redes sociais do catolicismo conservador, alertava mesmo para o precedente, com a pandemia, de que as igrejas viessem a ser decretadas como de funcionamento desnecessário, uma vez que teriam dado mostras de que poderiam funcionar de modo virtual; a "morte" da igreja estava sendo decretada:

É indissimulável o sentimento de vazio no coração dos católicos por uma Páscoa incompleta, distante do Santo Sacrifício da Missa, distante do sacramento da Comunhão, distante da confissão... A retórica dos bispos e dos padres - "assistam a missa pelas redes sociais" - tornou a situação ainda mais dolorosa, pois é de conhecimento comum entre os fieis que nada supre a assistência direta dos sacramentos. Simplesmente parece que a Páscoa não aconteceu! A Igreja nunca esteve tão subserviente aos governos seculares, tanto da ONU quanto dos governos locais. À mínima insinuação da conveniência do isolamento, toda a estrutura eclesiástica se trancou em uníssono, deixando os fieis do lado de fora. Os padres obedecem aos bispos e os bispos se aconchavam segundo suas próprias articulações internas, e o povo só assiste, atônito, gritando de fome. $E$ criou-se um precedente ainda pior: se um vírus é o bastante para fechar de maneira indiscriminada as Igrejas e interromper o culto público, então, já não haverá mais legitimidade, de agora em diante, para nunca mais acontecer nenhuma reunião de fieis, visto que existem e existirão milhões

33 Em 08 de abril, por exemplo, um grupo de católicos carismáticos, identificados como pertencentes à Comunidade Canção Nova, aproximou-se do presidente e disse que, "apesar da CNBB", "nós estamos com o senhor". Ler em: https://noticias.uol.com.br/ultimas-noticias/agencia-estado/2020/04/08/apesar-da-cnbbrenovacao-carismatica-catolica-diz-que-adeptos-apoiam-bolsonaro.htm. Acesso em 01 ago. 2020. 
de vírus em circulação, de menor ou maior letalidade, e todos somos vetores. De forma subliminar, o clero católico cometeu o mais absurdo "eclesiocídio", auto-relegando-se à perpétua clandestinidade (Disponível em: https: / / fratresinunum.com/2020/04/20/abram-as-igrejas-queremosas-missas-de-volta/. Acesso em 03 ago. 2020).

Outra postura dissonante do catolicismo em relação aos posicionamentos da CNBB se deu por meio da administração da Basílica Nacional de Aparecida. Tendo de encerrar a realização de missas, a pedido do Ministério Público, em 14 de março, o tempo ficaria ainda aberta à visitação do público por alguns dias. À medida em que a pandemia se alastrava pelo país, e também pelo estado de São Paulo, onde está localizada, as decisões em torno do fechamento dos templos se prorrogavam, afetando diretamente a Basílica. 4Foi então que, em 26 de maio, a igreja apresentou um pedido de liberação das atividades realizadas na Basílica, elencando como argumento central o fato de que haveria "sérios questionamentos técnicos" quanto à efetividade do isolamento social, uma vez que países como Suécia e Itália não teriam adotado "um mecanismo extremo e sofreram menos que outros" países que teriam adotado "modelo restritivo estranhamento defendido pela Promotoria".

Ainda em seu pedido, a igreja questionava o seguinte: "Se o presidente da República diz 'A', o governador diz 'B', o Ministério Público diz 'C' e o STF orienta a 'D'..., o que o cidadão deverá fazer? Em quem acreditar?”. Pondo-se contra a ciência e contra as orientações do próprio Vaticano, a administração da Basílica uniu-se aos argumentos negacionistas disseminados no Brasil.

No entanto, apesar das tensões e dissonâncias, o campo institucional católico manteve-se alinhado em oposição ao governo federal e às principais tendências do campo evangélico. Com resultados que demonstram a dissonância cognitiva espalhada, a última pesquisa nacional de aferição de opiniões de religiosos, feita pelo Instituto DataFolha em abril de 2020, mostrava-se um interessante mosaico: $90 \%$ dos católicos apoiavam o fechamento de escolas, contra $84 \%$ de evangélicos. ${ }^{34}$

34 Disponível em: https://www1.folha.uol.com.br/poder/2020/04/presidente-se-afasta-de-bolsonaristascatolicos-ao-minimizar-pandemia.shtml Acesso em 04 ago. 2020. 


\section{Considerações finais}

Intentamos, com este artigo, assinalar algumas fissuras entre as dimensões hierárquicas e laicais no catolicismo brasileiro, a partir de tomadas de posição com relação às recomendações em torno da pandemia de Covid-19. Se, por um lado, a comunicação oficial da CNBB se aproximou das recomendações científicas e se distanciou das ações do governo brasileiro, colaborando com a propagação das indicações sanitárias; movimentos católicos, e também os administradores da Basílica Nacional, tomaram o caminho do negacionismo, marchando para o lado oposto da Conferência e deslegitimando as recomendações médicas.

Em plena vigência da pandemia, o que se constatou no campo católico institucional foi o agravamento das tensões entre as organizações conservadoras e a CNBB, num debate mais amplo que opõe ciência e religião.

Constatou-se um divórcio entre as organizações conservadoras e as linhas pastorais do maior organismo católico brasileiro. Os conservadores comungam ideologicamente com as orientações e ideias do atual governo ao não criticar os graves problemas decorrentes da atuação do presidente contra as medidas sanitárias e de saúde, ratificando-as, e ao ir contra medidas de proteção e amparo social mais efetivas, em especial para grupos minoritários, como os povos indígenas e as populações negas.

A CNBB permaneceria, no entanto, estruturando a continuidade de um papel crítico e social, comunicando um valor que acredita evangélico e profundo, contra-hegemônico, "voz profética" e seguindo como elemento que estrutura as principais tendências do catolicismo no espaço público e politico conjugando um background religioso traduzido como comunicação política.

\section{Referências}

ALMEIDA, R. Bolsonaro Presidente: Conservadorismo, evangelismo e a crise brasileira. Novos Estudos Cebrap. São Paulo, 38/1, p.185-213, jan.-abr., 2019

BANDEIRA, O.; CARRANZA, B. Só o Brasil Cristão Salva da Covid-19. Boletim n.33, Ciências Sociais e Coronavírus, 5 maio de 2020.

BOURDIEU, P. Questões de Sociologia. Lisboa: Fim de Tempo, 2003. 
BOURDIEU, P. Os usos sociais da ciência: por uma sociologia clínica do campo Cientifico. São Paulo: Editora UNESP, 2004.

BOURDIEU, P. Para uma Sociologia da Ciência. Lisboa/Portugal: Edições 70, 2005.

BRUNEAU, T. Church and politics in Brazil: the genesis of change, Journal of Latin American Studies, 17, p. 271-293, 1985.

CARRANZA, B. Renovação Católica Carismática: Origens, Mudanças e Tendências. Aparecida, Editora Santuário, 2000.

GHIRALDELLI, P. JR. A República Brasileira: de Deodoro a Bolsonaro. São Paulo, CEFA Editorial, 2020.

INTROVIGNE M. Tradition, Family and Property (TFP) and the Heralds of The Gospel. The Religious Economy of Brazilian Conservative Catholicism. Alternative Spirituality and Religion Review, 7:2, pp 245-260, 2016

KLAIBER, J. The Church, Dictatorships and Democracy in Latin America. Eugene (Oregon), Wipf \& Stock, 1998.

MACHADO, M. D. C. Religião, Cultura e Política. Religião \& Sociedade, Rio De Janeiro, 32/2, pp 29-56, 2012.

MARIANO, R.; GERARDI, D. A América Latina em 2018 e ativismo político de evangélicos conservadores. Revista USP, São Paulo, 120, p. 61-76, jan./mar. 2019.

PY, F. Cristologia Pascoal Bolsonarista. Rio De Janeiro, 19 de abril de 2020, CEBI, Disponível em: via: https://cebi.org.br/noticias/cristologia-pascoal-bolsonarista/. Acesso em: 26 jul. 2020.

PY, F. Pandemia Cristofascista. São Paulo, Editora Recriar, 2020 b, Disponível em: https: //marketingeditorare.wixsite.com/ebooks Acesso em: 26 jul. 2020.

SILVEIRA, E. S. O Evangelho dos Produtos Canção Nova: salvação, consumo e mídia eletrônica. Estudos Teológicos (Online), 56, p. 420-434, 2016.

SILVEIRA, E. S. Glossolalias, justiça social e báculos episcopais - narrativas míticas entre carismáticos, progressistas e conservadores. In: SILVEIRA, ES DA; SAMPAIO, DS (ed.). Narrativas Míticas: análise das histórias que as religiões contam. Petrópolis, Editora Vozes, p. 25-70, 2018.

SILVEIRA, E. S. Padres Conservadores em Armas: o discurso público da Guerra Cultural entre Católicos. Reflexão (PUCCAMP), Campinas, 43/2, p. 289-309, 2019. 


\section{Como citar este artigo}

SILVA, Emanuel Freitas da; SILVEIRA, Emerson José Sena da. Quando a religião (des)comunica a ciência: o catolicismo brasileiro e a pandemia de Covid-19. Revista Dispositiva. [on-line] Disponível em: <http://periodicos.pucminas.br/index.php/dispositi va> Dossiê: Comunicação, política e saúde. Editoras Responsáveis: Fernanda Sanglard e Vanessa Veiga de Oliveira. Volume 9, Número 16, Belo Horizonte, dezembro de 2020, p. 188-206. Acesso em "dia/mês/ano".

Texto recebido em: 04/08/2020

Texto aprovado em: 10/08/2020 